\title{
Review on research and development of heat resistant Magnesium alloy
}

\author{
Sanling $\mathrm{Fu}^{1,3}$ \\ ${ }^{1}$ School of Materials Science and Engineering, \\ Xi an University of Technology, Xi an 710048, China; \\ ${ }^{3}$ School of Physics and Engineering, \\ Henan University of Science and Technology, Luoyang, \\ 471023 China
}

\author{
Xiaotian Jing ${ }^{1}$ \\ ${ }^{1}$ School of Materials Science and Engineering, \\ $\mathrm{Xi}$ an University of Technology, \\ $\mathrm{Xi}$ an 710048 , China
}

\section{Zhi Chen ${ }^{2}$}

${ }^{2}$ School of Materials Science and Engineering, Henan University of Science and Technology, Luoyang 471023, China

\begin{abstract}
Magnesium alloys as the emerging commercial metal structure material have excellent specific properties and stability, which is more and more important for researcher. The magnesium alloy of Mg-Al series, Mg-Zn series, Mg-RE series included Mg-Y series alloy, Mg-Gd-Y series alloy, Mg-RE-Zr series alloy, Mg-RE-Ag series alloy were summarized, the existing heat resistant magnesium alloy still exists insufficient heat resistance or poor comprehensive mechanical properties and processing property except heat-resistant magnesium alloys with Mg-RE. The development trends of heat resistant magnesium alloy were discussed and analyzed, Little multicomponent alloying is effective ways to improve the performance of heat resistant magnesium alloy, the alloy manufacturability was improved in order to industrialized production, and the melt purification, the casting and forming technology were researched in order to improve the comprehensive performance of heatresistant magnesium alloys.
\end{abstract}

Keywords- review; magnesium alloy; heat resistant; $\mathrm{Mg}$-Zn; $M g-A l ; M g-R E$

\section{INTRODUCTION}

Magnesium alloys as the emerging commercial metal structure material have excellent specific strength and stiffness, excellent casting forming technology, machining and surface treatment properties, exceptional dimensional stability, high damping capacity and high recycle ability. The research and development of magnesium alloys for practical industrial application have obviously increased worldwide during the last few decades based on these superior properties of Magnesium alloys and the product requirement of light weighted structures. Magnesium alloys are playing an increasingly important role in

\author{
Quanan $\mathrm{Li}^{1,2}$ \\ ${ }^{1}$ School of Materials Science and Engineering, \\ Xi an University of Technology, Xi an 710048, China; \\ ${ }^{2}$ School of Materials Science and Engineering, \\ Henan University of Science and Technology, Luoyang \\ 471023, China
}

\author{
Qing Zhang ${ }^{2}$ \\ ${ }^{2}$ School of Materials Science and Engineering, \\ Henan University of Science and Technology, \\ Luoyang 471023 , China
}

\author{
Wenjian $\mathrm{Liu}^{2}$ \\ ${ }^{2}$ School of Materials Science and Engineering, \\ Henan University of Science and Technology, \\ Luoyang 471023, China
}

automotive, aircraft, and electronic products instead of steel, aluminum alloy and engineering plastics materials [1].

Magnesium alloys can be divided into two types included the cast magnesium alloys and the wrought magnesium alloys. Statistically, more than $90 \%$ of the magnesium alloy structural components are produced by casting process, especially the $\mathrm{AZ}$ series cast magnesium alloys, the widely used magnesium alloys belong to $\mathrm{Mg}-\mathrm{Al}$ series included AZ91 and AM60, which has good combination of castability and low cost. However, the application of these magnesium alloys has been limited because of their poor mechanical properties and thermal stability. Compared with cast magnesium alloys, the wrought magnesium alloys have a more promising perspective of application, which is the reason why research and development of high performance wrought magnesium alloys, novel wrought magnesium processing technology, and producing high quality wrought magnesium alloy products are an important objective [2].

But the strength and the plasticity of the magnesium alloy are generally lower than those of aluminum alloy. In addition, the shortcoming of the high temperature performance is one of the main reasons on widely used in magnesium alloy, the application of magnesium alloy was limited due to the decrease of the strength and the creep resistance when the temperature rises. The problems of the magnesium alloy research included the strength and the toughness will be solved at room temperature and high temperature strength. The magnesium alloy at room temperature and high temperature mechanical properties reinforcement ways have solid-solution strengthening, precipitation strengthening and dispersion strengthening [3]. 


\section{Mg-Al SERIES MAGNESIUM ALLOY}

$\mathrm{Mg}-\mathrm{Al}$ series magnesium alloy is most widely applied in society fields included AS alloy and AE alloy, the research of the magnesium alloy is quite mature after decades of thorough research [4]. Amjad [5] had researched the mechanical properties of hydrogenated $\mathrm{Mg}-\mathrm{Al}$ magnesium alloys with various aluminum content, and results showed that the ductility, yield strength and ultimate tensile strength of the material decreased while the hardness increased with increasing the Al content, and the microscopic observations of cross-sections of the test sample with various $\mathrm{Al}$ content indicated that hydrogen cracks extended deeply with the increase of the Al content in the $\mathrm{Mg}-\mathrm{Al}$ alloys. Unigovski [6] researched creep behavior of pure magnesium and $\mathrm{Mg}-\mathrm{Al}$ alloys in active environments, the cracking and final creep-rupture of pure $\mathrm{Mg}$ originate in a transcrystalline manner in comparison with intercrystalline fracture of the alloys. Cracks are observed in pure $\mathrm{Mg}$ at the primary creep stage, but their depth and amount are relatively small. The effect of environment on the creep behavior of magnesium is connected, mainly, with plasticization of metal assisted by chemical reactions. And anodic dissolution of $\mathrm{Mg}$ is enhanced by creep stress.

The $\mathrm{Mg}$ concentration profiles were measured in the precipitate free zones (PFZ) and also in the grains of Al 9 $\mathrm{mol} \% \mathrm{Mg}$ based alloys using analytical electron microscopy. There was significant supersaturation of the $\mathrm{Mg}$ concentration in PFZ even after prolonged aging. Also, the presence of a steep concentration gradient was observed near the $\beta\left(\mathrm{AI}_{3} \mathrm{Mg}_{2}\right)$ precipitate on the grain boundary. This concentration profile was scarcely modified by the $\mathrm{Cu}$ addition. However, the $\mathrm{Zn}$ addition made the gradient more gentle. The supersaturated state was also observed in the intermediate region between the precipitates inside the grain, even though it depended largely on the interspacing between them. Furthermore, it was suggested that a very low solute-concentration region existing near the $\beta$ precipitate in the grain-boundaries will cause poor resistance to the stress corrosion cracking of the alloys [7].

\section{Mg-Zn SERIES MAGNESIUM ALLOY}

The development direction of the heat resistant magnesium alloy with the high strength and the high tenacity was $\mathrm{Zn}$ as addition elements without aluminum or less aluminum. In the $\mathrm{Mg}-\mathrm{A} 1-\mathrm{Zn}$ series alloy, $\mathrm{Zn}$ elements on the influence of mechanical properties can be summed up as follows: the yield strength and the tensile strength will enhance and the elongation will decrease with the increase of $\mathrm{Zn}$ elements when $\mathrm{Zn}$ content is less than $6 \%$, and the tensile strength and the elongation will decrease with the increase of $\mathrm{Zn}$ elements when $\mathrm{Zn}$ content is more than 6\% [8]. The addition of $\mathrm{Zn}$ element is effective on improving creep strength of $\mathrm{Mg}-\mathrm{Y}$ solid solution alloys at temperatures $550-650 \mathrm{~K}$ because $\mathrm{Zn}$ suppresses the non-basal slip that operates predominantly at such temperatures. This suppression is caused by the formation of planar defects on the $\left(\begin{array}{llll}0 & 0 & 0 & 1\end{array}\right)$ plane and confinement of dislocations in the basal plane due to a decrease in stacking fault energy [9].

The interaction between $\mathrm{Zn}$ and RE additions will play important influence for the properties of the heat resistant magnesium alloy. The casting properties and creep resistance of the magnesium alloy will be improved when the rare earth elements is added to the $\mathrm{Mg}-\mathrm{Zn}$ alloy. Effects of $\mathrm{Zn}$ and $\mathrm{RE}$ additions on the solidification behavior of Mg-9Al alloy were studied. $\mathrm{Zn}$ additions increased the quantity of phase and its continuity at grain boundaries. Eutectic temperature was also decreased because of $\mathrm{Zn}$ enrichment. $\mathrm{Zn}$ additions increased the hot tearing susceptibility of the Mg-9Al alloy, and RE additions slowed down the temperature decrease at the initial stage of solidification, but had little effect on the hot-tearing susceptibility coefficient (HSC). However, RE additions exceeding 1.6 wt. \%, HSC was increased. With $\mathrm{Zn}$ and RE mixed additions, $\mathrm{Zn}$ is the principal factor to affect the endsolidifying temperature. With $\mathrm{Zn}$ content exceeding $0.8 \mathrm{wt}$ \% $\mathrm{RE}$ additions can decrease HSC distinctly [10]. Xu [11] investigated the mechanical properties of as-cast $\mathrm{Mg}-\mathrm{Zn}-\mathrm{Y}-\mathrm{Zr}$ $\mathrm{Mg}$ alloys with $\mathrm{Zn} / \mathrm{Y}$ ratio about 0.97 . The alloy with $\mathrm{Zn} 3.93$ wt. \% and Y 4.14 wt. \% has the highest strength when $\mathrm{Zn} / \mathrm{Y}$ ratio is constant, and the alloys are mainly composed of $\alpha-\mathrm{Mg}$ matrix and $\mathrm{W}$-phase. With the contents of $\mathrm{Zn}$ and $\mathrm{Y}$ increasing, the diffraction peaks of W-phase are gradually intensified. In addition, microstructure observation indicated that the grain boundaries are gradually coarsened by W-phase with the increase of $\mathrm{Y}$ and $\mathrm{Zn}$ contents [11].

\section{Mg-RE SERIES ALLOY}

Rare earth (RE) elements in the magnesium has great solid solubility limit, and the solid solubility sharply reduced with temperature drop, so the larger degree of supersaturation will be obtained, the dispersion strengthening phase will be precipitated in the subsequent aging process. The precipitated phase with RE usually has high thermal stability, and the diffusion rate of the RE elements in magnesium matrix is slower at the same time, which can make Mg-RE alloy with higher temperature strength and excellent creep performance, and maintain a higher strength at $200{ }^{\circ} \mathrm{C}$.

\section{A. $\quad$ Mg-Y series alloy}

$\mathrm{Y}$ is considered to be the most effective on improving the high temperature properties of magnesium alloy elements in all of the rare earth element, and its solid solubility will be lower with the lower temperature, it can be produced excellent solid solution strengthening and aging reinforcement in magnesium. Thus a series of Mg-Y-RE base heat resistant magnesium alloy was developed. $\mathrm{Zn}$ element used as addition is a kind of effective method in order to reduce the experimental cost of $Y$ element to join and not sacrifice $\mathrm{Mg}-\mathrm{Y}$ alloy intensity. Panigrahi [12] have researched the combined effect of forging and aging on microstructural evolution and mechanical properties of a Mg-Y-RE alloy by employing hardness measurements, tensile tests, OM, SEM and EBSD analysis. The temper treated bulk Mg-Y-RE alloy samples were subjected to forging for microstructural refinement and subsequent aging to maximize the strength-ductility combination. The forged samples with peak aging treatment for $60 \mathrm{~h}$ at $180{ }^{\circ} \mathrm{C}$ exhibited an excellent combination of high strength and high ductility. The combined effect of grain refinement, work hardening, precipitation strengthening and recovery is responsible for the simultaneous improvement of 
both strength and ductility. A comparative study of age hardening response of forged samples and as received samples showed higher hardenability in forged samples [12].

The hardness of the alloys increased in the as-quenched and aged-peak conditions with increasing Y content. The aging temperature of the most remarkable age hardening response is $250{ }^{\circ} \mathrm{C}$ when the $\mathrm{Y}$ element is $7 \%$. The tensile strength of the alloys increased monotonously with increasing $\mathrm{Y}$ content, and $\mathrm{Mg}-4 \mathrm{Ho}-7 \mathrm{Y}-0.6 \mathrm{Zr}$ exhibited the maximum ultimate tensile strength and yield strength at peak hardness, and the values were 240 and $165 \mathrm{MPa}$ at room temperature, and 204 and $131 \mathrm{MPa}$ at $250{ }^{\circ} \mathrm{C}$, respectively. The improvement in strength appeared to be associated with $\beta^{\prime}$ and/or equilibrium $\mathrm{Mg}_{24} \mathrm{Y}(\mathrm{Ho})_{5}$ precipitates and high dense dislocation [13].

Thermodynamic modeling and optimization of the $\mathrm{Gd}-\mathrm{Mg}$, $\mathrm{Mg}-\mathrm{Y}, \mathrm{Gd}-\mathrm{Y}$ binary systems and the $\mathrm{Gd}-\mathrm{Mg}-\mathrm{Y}$ ternary system have been critically carried out by means of the Calculation of Phase Diagram (CALPHAD) technique. The solution phases are modeled with the Redlich-Kister equation. The Compound Energy Model has been used to describe the thermodynamic functions of the intermetallic compounds in these systems [14]. The CALPHAD method was used to select ternary alloys from $\mathrm{Mg}-\mathrm{Zn}-\mathrm{Y}$ system in order to determine the role of precipitates in the microstructure and texture evolution of $\mathrm{Mg}$ during and after deformation. The constituent phases in the as-cast $\mathrm{Mg}-6 \mathrm{Zn}-1.2 \mathrm{Y}$ alloy are $\alpha-\mathrm{Mg}$ solid solution phase and $\mathrm{I}\left(\mathrm{Mg}_{3} \mathrm{YZn}_{6}\right)$ intermetallic phase. The as-cast $\mathrm{Mg}-5 \mathrm{Zn}-2 \mathrm{Y}$ alloy is composed of $\alpha-\mathrm{Mg}$, I and $\mathrm{W}\left(\mathrm{Mg}_{3} \mathrm{Y}_{2} \mathrm{Zn}_{3}\right)$ phases. The intermetallics in the two alloys form by eutectic reaction, which in $\mathrm{Mg}-5 \mathrm{Zn}-2 \mathrm{Y}$ alloy results in initially W-phase formation and ultimately I-phase formation during solidification. After heat treatment, the $\mathrm{Mg}-6 \mathrm{Zn}-1.2 \mathrm{Y}$ and $\mathrm{Mg}-5 \mathrm{Zn}-2 \mathrm{Y}$ alloys contain nearly the same amount of ternary intermetallics in equilibrium with $\alpha-\mathrm{Mg}$ solid solution phase. [15].

\section{B. $M g-G d-Y$ series alloy}

In recent years, people to Mg-Gd-Y based Mg-Gd-Y-Mn and $\mathrm{Mg}-\mathrm{Gd}-\mathrm{Y}-\mathrm{Zr}$ system alloy is conducted on the research, according to the Drits research, including Mn of Mg-Gd-Y alloy has very excellent room temperature and high temperature mechanical properties. The compounds at the grain boundaries are mainly $\mathrm{Mg}_{24} \mathrm{Y}_{5}, \mathrm{Mg}_{41} \mathrm{Nd}_{5}$, and $\mathrm{Mg}_{5} \mathrm{Gd}$ phases. The average grain size of as-cast alloys is $50-60 \mu \mathrm{m}$, $\mathrm{Mg}_{5} \mathrm{Gd}$ phases mostly decompose and dissolve into the matrix after the treatment for $24 \mathrm{~h}$ at $535{ }^{\circ} \mathrm{C}$, and the disperse spotted phases are mainly $\mathrm{Mg}_{24} \mathrm{Y}_{5}$ and $\mathrm{Mg}_{41} \mathrm{Nd}_{5}$ phases. The grain size is refined and some grains abnormally grow up to about $40 \mu \mathrm{m}$ after extruding and ageing for $5 \mathrm{~h}$ at $250{ }^{\circ} \mathrm{C}$. With Gd content increasing, the ultimate tensile strength, yield strength of ascast alloys and the extruded bars after ageing are improved, but the elongation is decreased [16]. The effects of $\mathrm{Gd}$ and Y additions on the microstructure and properties of $\mathrm{Al}-\mathrm{Zr}-\mathrm{Mg}-$ $\mathrm{Cu}-\mathrm{Zr}$ alloys were researched by $\mathrm{OM}$, tensile test, SEM, EPMA and TEM. The combined additions of Gd and $Y$ to the $\mathrm{A} 1-\mathrm{Zn}-\mathrm{Mg}-\mathrm{Cu}-\mathrm{Zr}$ alloys effectively retard the mergence and growth of the sub-grain during the recovery process, and significantly inhibit the recrystallization of Al matrix. $\sigma_{\mathrm{b}}, \sigma_{0.2}$ and $\delta$ are improved with increasing $\mathrm{Gd}$ and $\mathrm{Y}$ content, and the improving amplitudes reach $11.49 \%, \quad 14.61 \%, \quad 63.11 \%$ respectively and have better relative intracrystalline solubility [17].

A number of $\mathrm{Mg}-\mathrm{Gd}, \mathrm{Mg}-\mathrm{Y}$ binary and $\mathrm{Mg}-\mathrm{Gd}-\mathrm{Y}$ ternary alloys are investigated in terms of solid solution strengthening efficiency. It is found that both gadolinium and yttrium in solid solution give a c" concentration dependence of the yield strength, where $\mathrm{c}$ is the solute atom concentration and $\mathrm{n}=1 / 2$ or $2 / 3$. This simplified analysis illustrates that we are able to satisfactorily predict the ternary solid solution strengthening in $\mathrm{Mg}-\mathrm{Gd}-\mathrm{Y}$ alloys. Gd and $\mathrm{Y}$ in solid solution are found to give a considerably higher strengthening effect than $\mathrm{Al}$ and $\mathrm{Zn}$. It is suggested that, in addition to the classical size and modulus model, the valency effect may account for the enhanced strengthening of $\mathrm{Gd}$ and $\mathrm{Y}$ in $\mathrm{Mg}$ [18]. The cooling rate has significant effects on the microstructure of Mg-Gd-Y-Zr alloy. The increase of cooling rate can refine obviously the solidified microstructure. The grains are refined and the morphology of the primary phases is changed from the coarse to the thin. The eutectic distributes more homogeneously and its volume fraction decreases with the increase of cooling rate. Higher cooling rate can increase the solid solubility, which contributes to the reduction of dendritic segregation of solutes of Gd and $\mathrm{Y}$ in Mg-Gd-Y-Zr alloy [19].

\section{Mg-RE-Zr series alloy}

$\mathrm{Zr}$ can make the cast structure significant refinement, and improve the mechanical properties of the alloy. Two Al-MgMn alloys having similar compositions but with and without $\mathrm{Zr}$ addition were subjected to equal channel angular pressing at $350{ }^{\circ} \mathrm{C}$, followed by water quenching or air cooling. A series of annealing experiments were conducted at various temperatures from 400 to $460{ }^{\circ} \mathrm{C}$ on the water-quenched alloys. Fine structures with grain sizes of about $1-2 \mu \mathrm{m}$ were obtained in these alloys after six passes. The water-quenched alloy containing $\mathrm{Zr}$ exhibited finer structure and higher strength compared to the $\mathrm{Zr}$-free alloy in the same cooling condition, which was due to the existence of $\mathrm{Al}_{3} \mathrm{Zr}$ dispersoids. And in air cooling condition, the difference of strength between these two alloys increased further. This was because that the static recovery and static recrystallization during the air cooling process decreased the strength of the $\mathrm{Zr}$-free alloy, while the fine $\mathrm{Al}_{3} \mathrm{Zr}$ dispersoids inhibited the restoration in the alloy containing $\mathrm{Zr}$. In addition, in the annealing experiments, secondary recrystallization took place in the $\mathrm{Zr}$-free alloy annealed at $410{ }^{\circ} \mathrm{C}$ for $1 \mathrm{~h}$, and it was completed when annealed at $460{ }^{\circ} \mathrm{C}$ for $1 \mathrm{~h}$. While the alloy containing $\mathrm{Zr}$ kept stable up to $460{ }^{\circ} \mathrm{C}$ for the pinning effect of the $\mathrm{Al}_{3} \mathrm{Zr}$ dispersoids. Tensile tests showed that the strength of the $\mathrm{Zr}$ free alloy decreased dramatically after annealing at $460{ }^{\circ} \mathrm{C}$ for $1 \mathrm{~h}$, while the alloy containing $\mathrm{Zr}$ exhibited almost no decline at the same condition [20].

The Mg-5.3 wt.\% Zn-1.13 wt.\% Nd-0.51 wt.\% La-0.28 wt. $\% \mathrm{Pr}-0.79$ wt. $\% \mathrm{Zr}$ alloy prepared by direct chill casting is subjected to hot extrusion. The effects of extrusion ratio and temperature on microstructure and tensile mechanical properties have been studied. The results indicate coarse grains of as-cast alloys are refined with extrusion ratio increasing from 0 to 9 . The eutectic constituents are elongated along 
extrusion direction. However, further increase of extrusion ratio has a little influence on grain refinement and the improvement of mechanical properties of the alloy. Dynamic recrystallisation is the main mechanism of grain refinement during hot extrusion. Raising extrusion temperature results in grain coarsening. Grain shape becomes more equiaxed-like with raising extrusion temperature. At the same time, mechanical properties decrease with the increase of extrusion temperature [21].

\section{D. $M g-R E-A g$ series alloy}

Silver in the magnesium solid solubility is bigger, and the highest can amount to $15.5 \%$. Ag to join in the $\mathrm{Mg}$ after clearance solution way into magnesium lattice, cause lattice happen non spherical symmetric distortion, produce strong solid solution strengthening effect. Ag and RE when join can improve alloy high temperature tensile and high temperature creep performance. Bai [22] have researched the effects of Er element on microstructures and fatigue fracture behavior of an $\mathrm{Al}-\mathrm{Cu}-\mathrm{Mg}-\mathrm{Ag}$ alloy. Microstructural examinations revealed that the precipitation kinetics of $\Omega$ phase was distinctly retarded by promoting the formation of $\theta^{\prime}$ phase with the Er addition during the initial aging. The fatigue crack propagation resistance of Er-containing microstructure was significantly enhanced arising from the presence of the crystallographic secondary cracks, which was directly relative to the large grain size. Results also suggested that the dendritic substructure of as-cast $\mathrm{Al}-\mathrm{Cu}-\mathrm{Mg}-\mathrm{Ag}$ alloy was refined remarkably by $\mathrm{Er}$ addition [22].

\section{CONCLUSION}

As can be showed that the heat resistant magnesium alloy still existed insufficient heat resistance or poor comprehensive mechanical properties and the processing property except heat resistant magnesium alloys with Mg-RE. The heat-resistant magnesium alloys should be in accordance with the following design and development ideas to adapt to the actual application from the angle of the need of the development.

(1) Little multi-component alloying is effective ways to improve the performance of heat resistant magnesium alloy included the properties of the heat resistance, mechanical properties, corrosion resistance. The research core of the low cost and high performance heat resistant magnesium exerted their interaction between many series alloy elements and trace elements in order to the alloy properties.

(2) The alloy manufacturability was improved in order to industrialized production, and the melt purification, casting and forming new technology were researched in order to improve the comprehensive performance of heat-resistant magnesium alloys. The dispersion strengthened magnesium alloy and the magnesium matrix composite materials and some new technology included the rapid solidification, the semi-solid technology will develop the new field for the new development and application of heat-resistant magnesium alloys.

\section{REFERENCES}

[1] Qing Zhang, Quan-an Li and Xing-yuan Zhang, et al. "Research Progress of Heat Resistant Mg-Gd System Magnesium Alloy".
Foundry, Vol. 60, pp. 1080-1083, 2011.

[2] Z. Yang, J.P. Li, and J.X. Zhang, et al "Review on Research and Development of Magnesium Alloys", Acta Metallurgica Sinica (English Letters), Vol. 21, pp. 313-328, 2008.

[3] Guangsen Chen, Guohua Wu and Yuguang Huang, et al. "Review on Research of High Strength, High Toughness and $\mathrm{H}$ eat-resistant Magnesium Alloy", Foundry engineering, Vol. 31, pp. 30-33, 2007.

[4] Jun Chen, Quanan Li and Xiaofeng Li, et al. "The Latest Development of Mg-A1 Series Heat resistant Magnesium Alloy", Rare Metals and Cemented Carbides, Vol. 37, pp. 50-55, 2009.

[5] Amjad Saleh El-Amoush. "Effect of aluminum content on mechanical properties of hydrogenated $\mathrm{Mg}-\mathrm{Al}$ magnesium alloys" Journal of Alloys and Compounds, Vol. 463, pp. 475-479, 2008.

[6] Ya. Unigovski, Z. Keren and A. Eliezer, et al. "Creep behavior of pure magnesium and $\mathrm{Mg}-\mathrm{Al}$ alloys in active environments", Materials Science and Engineering: A, Vol. 38, pp. 188-197, 2005.

[7] H. Yukawa, Y. Murata and M. Morinaga, et al. "Heterogeneous distributions of Magnesium atoms near the precipitate in Al-Mg based alloys", Acta Metallurgica et Materialia, Vol. 43, pp. 681-688,1995.

[8] Jianchang Xie, Quanan Li and Xiaoqiang Wang, et al. "Microstructure and mechanical properties of AZ81 magnesium alloy with $\mathrm{Y}$ and $\mathrm{Nd}$ elements". Transactions of Nonferrous Metals Society of China, Vol. 18 , pp. 303-308, 2008.

[9] M. Suzuki, T. Kimura and J. Koike, et al. "Strengthening effect of $\mathrm{Zn}$ in heat resistant $\mathrm{Mg}-\mathrm{Y}-\mathrm{Zn}$ solid solution alloys", Scripta Materialia, Vol. 48, pp. 997-1002, 2003.

[10] Yeshuang Wang, Qudong Wang and Chunjiang Ma, et al. "Effects of $\mathrm{Zn}$ and $\mathrm{RE}$ additions on the solidification behavior of $\mathrm{Mg}-9 \mathrm{Al}$ magnesium alloy", Materials Science and Engineering: A, Vol. 342, pp. 178-182, 2003.

[11] D.K. Xu, W.N. Tang and L. Liu et al. "Effect of W-phase on the mechanical properties of as-cast $\mathrm{Mg}-\mathrm{Zn}-\mathrm{Y}-\mathrm{Zr}$ alloys", Journal of Alloys and Compounds, Vol. 461, pp. 248-252, 2008.

[12] S.K. Panigrahi, W. Yuan and R.S. Mishra, et al. "study on the combined effect of forging and aging in $\mathrm{Mg}-\mathrm{Y}-\mathrm{RE}$ alloy", Materials Science and Engineering: A, Vol. 530, pp. 28-35, 2011.

[13] J. Wang, D.P. Zhang and D.Q. Fang, et al. "Effect of Y for enhanced age hardening response and mechanical properties of $\mathrm{Mg}-\mathrm{Ho}-\mathrm{Y}-\mathrm{Zr}$ alloys", Journal of Alloys and Compounds, Vol. 454, pp. 194-200, 2008.

[14] Cuiping Guo, Zhenmin Du and Changrong Li. A thermodynamic description of the Gd-Mg-Y system, Calphad, Vol. 31, pp. 75-8, 2007.

[15] S.A. Farzadfar, M. Sanjari and I.-H. Jung, et al. "Experimental and calculated phases in two as-cast and annealed $\mathrm{Mg}-\mathrm{Zn}-\mathrm{Y}$ alloys". Materials Characterization, Vol. 63, pp. 9-16, 2012.

[16] Kui Zhang, Xing-gang Li and Yong-jun Li, et al. "Effect of Gd content on microstructure and mechanical properties of Mg-Y-RE-Zr alloys", Transactions of Nonferrous Metals Society of China, Vol. 18 pp. s12s16, 2008.

[17] Xingguo Zhang, Feiqiang Mei and Huanyue Zhang, et al. 'Effects of $\mathrm{Gd}$ and $\mathrm{Y}$ additions on microstructure and properties of $\mathrm{Al}-\mathrm{Zn}-\mathrm{Mg}-$ $\mathrm{Cu}-\mathrm{Zr}$ alloys". Materials Science and Engineering: A, Vol. 552, pp. 230-235, 2012.

[18] L. Gao, R.S. Chen and E.H. Han. " Effects of rare-earth elements Gd and $\mathrm{Y}$ on the solid solution strengthening of Mg alloys", Journal of Alloys and Compounds, Vol. 481, pp.379-384, 2009.

[19] Jixue Zhou, Yuansheng Yang and Wenhui Tong, et al. "Effect of Cooling Rate on the Solidified Microstructure of Mg-Gd-Y-Zr Alloy", Rare Metal Materials and Engineering, Vol. 39, pp. 1899-1902, 2010.

[20] Jiangli Ning and Daming Jiang. "Influence of $\mathrm{Zr}$ addition on the microstructure evolution and thermal stability of $\mathrm{Al}-\mathrm{Mg}-\mathrm{Mn}$ alloy processed by ECAP at elevated temperature", Materials Science and Engineering: A, Vol.452-453, pp. 552-557, 2007.

[21] Qiang Chen, Dayu Shu and Zude Zhao, et al. "Microstructure development and tensile mechanical properties of $\mathrm{Mg}-\mathrm{Zn}-\mathrm{RE}-\mathrm{Zr}$ magnesium alloy", Materials \& Design, Vol. 40, pp. 488-496, 2012.

[22] Song Bai, Zhiyi Liu and Yuntao Li, et al. 'Microstructures and fatigue fracture behavior of an $\mathrm{Al}-\mathrm{Cu}-\mathrm{Mg}-\mathrm{Ag}$ alloy with addition of rare earth Er", Materials Science and Engineering: A, Vol. 527, pp. 18061814,2010 